\title{
Hubungan Komunikasi Interpersonal Perawat Terhadap Kepatuhan Minum Obat Pasien Diabetes Melitus Tipe 2
}

\section{Relation of Nurse Interpersonal Communication to Compliance in Taking Medication of Type 2 Diabetes Mellitus Patients}

\author{
Gad Datak $^{1}$, Irene Febriani ${ }^{2 *}$ \\ 1. Jurusan Keperawatan, Poltekkes Kemenkes Palangka Raya \\ 2. Jurusan Kebidanan, Poltekkes Kemenkes Palangka Raya \\ *Email Korespondensi : irene.febriani@poltekkes_palangkaraya.ac.id
}

\begin{abstract}
Abstrak
LatarBelakang :Kepatuhan penggunaan obat adalah upaya agar tercapai keberhasilan terapi, kepatuhan penggunaan obat antidiabetik merupakan hal penting karena jika tidak tercapai akan menyebabkan terjadinya kegagalan terapi, yang dapat menyebabkan komplikasi. Salah satu strategi untuk meningkatkan ketaatan adalah memperbaiki komunikasi antara dokter maupun perawat dengan pasien untuk menumbuhkan dan meningkatkan hubungan interpersonal.

Tujuan : Untuk mengetahui hubungan komunikasi interpesonal perawat terhadap kepatuhan minum obat pasien diabetes melitus tipe 2 di Puskesmas Pahandut Palangka Raya.

Metode :Penelitian ini merupakan penelitian kuantitatif. Populasi penelitian ini adalah semua pasien dengan Diabetes Melitus tipe 2 sebanyak 103 orang. Menggunakan teknik purposive sampling sebanyak 52 responden. Penelitian ini dilakukan dari bulan April sampai Mei 2019.

Hasil :Hasil penelitian menunjukkan nilai OR 1,109 pada (95\% CI : 0,92 - 2,50) P-Value $\leq$ 0,001, terdapathubungan antara komunikasi interpersonal perawat terhadap kepatuhan minum obat pada pasien diabetes melitus tipe 2 di Puskesmas Pahandut Palangka Raya.

Kesimpulan : Perawatagar dapat meningkatkan pengetahuan dan keterampilan dalam berkomunikasi dengan klien selama memberikan asuhan keperawatan sehingga meningkatkan kepatuhan klien untuk minum obat dan meningkatkan ketaatan klien dalam menjalankan terapi.
\end{abstract}

Kata kunci: Diabetes, Komunikasi, Kepatuhan

\begin{abstract}
Background: Compliance with drug use is an effort to achieve therapeutic success, adherence to the use of antidiabetic drugs is important because if not achieved will lead to therapy failure, which can cause complications. One strategy to increase obedience is to improve communication between doctors and nurses and patients to foster and improve interpersonal relationships.

Objective : The aim to find out the relationship between nurses interpersonal communication and medication adherence for patients with type 2 diabetes mellitus at Pahandut Palangka Raya Health Center. This research is quantitative research. The study population was all 103 patients with type 2 diabetes mellitus. Using a purposive sampling technique of 52 respondents. This research was conducted from April to May 2019.

Result :The result showed odd ratio (OR) value is 1,109 at (95\% CI : 0,92 - 2,50) P-Value $\leq 0,001$, there was a relationship between nurses interpersonal communication and medication adherence in patients with type 2 diabete mellitus at Haleth Center in PahandutPalangka Raya.

Conclusion :Nurse can improve their knowledge and skills in communicating with clients while providing nursing care to increase client compliance with medication and increase client compliance in carrying out therapy.
\end{abstract}

Keywords: Diabetes, Communication, Complience 


\section{PENDAHULUAN}

Diabetes Melitus (DM) merupakan suatu penyakit kronis yang memerlukan strategi dan penanganan untuk mengurangi berbagai resiko terkait peningkatan kadar glikemik. Diabetes melitus seringkali undiagnosed selama bertahun-tahun karena kadar glikemik meningkat secara bertahap dan gejala yang dirasakan pasien masih ringan. Pasien dengan kondisi peningkatan kadar glikemik memiliki resiko untuk mengalami komplikasi penyakit mikrovaskuler dan makrovaskuler. Komplikasi jangka pendek yang akan dialami penderita DM adalah kadar glikemik yang tinggi dalam waktu yang panjang dapat menyebabkan kerusakan jaringan dan organ tubuh dan ketoasidosis yang terjadi saat tubuh tidak mampu menggunakan glukosa sebagai energi karena kekurangan insulin(1).

Komplikasi jangka panjang DM adalah kerusakan mata, gangguan pada jantung dan pembuluh darah, neuropati, dan stroke. Jumlah penderita diabetes selalu meningkat setiap tahunnya, WHO memprediksi pada tahun 2030 jumlah pasien diabetes mencapai 21,3 juta(2). Prevalensipenyandang DM tahun 2015 adalahsebanyak 415 juta jiwa di seluruh dunia dandiprediksi akan terus meningkat mencapai642 juta jiwa pada tahun 2024, dan Indonesia masuk dalam 10negara terbesar penderitaDM di dunia dan menempati urutan ke-7denganjumlah penyandang sebanyak 10juta jiwa(3). Berdasarkan pemeriksaan gula darah, prevalensi diabetes melitus naik dari 6,9\% menjadi $8,5 \%$ (4).

Kepatuhan penggunaan obat adalah salah satu upaya agar tercapai keberhasilan terapi, kepatuhan penggunaan obat antidiabetik merupakan hal penting karena jika tidak tercapai keberhasilan terapi akan menyebabkan terjadinya kegagalan terapi, kegagalan terapi adalah penyebab timbulnya penyakit tambahan yang lain atau sering disebut komplikasi(5). Pasien diabetes melitus beresiko mendapatkan komplikasi akut maupun kronis akibat kegagalan terapi. Komplikasi akut pada penderita diabetes melitus antara lain hiperglikemia dan hipoglikemia dan komplikasi kronik antara lain mikrovaskulerseperti retinopati, nefropati, neuropati dan makrovaskuler seperti jantung koroner, stroke, dan gangren/ulkus pada kaki(6).

Salah satu strategi untuk meningkatkan ketaatan adalah memperbaiki komunikasi antara dokter maupun perawat dengan pasien. Kualitas interaksi antara petugas kesehatan dan pasien merupakan bagian yang penting dalam menentukan derajat kepatuhan. Meningkatkan interaksi petugas kesehatan dengan pasien adalah suatu hal penting untuk memberikan umpan balik pada pasien setelah memperoleh informasi tentang diagnosis.Untuk meningkatkan interaksi tenaga kesehatan dengan pasien, diperlukan suatu komunikasi yang baik oleh tenaga kesehatan. Komunikasi seorang tenaga kesehatan dapat memberikan informasi yang lengkap gunameningkatkan pengetahuan pasien, sehingga diharapkan lebih dapat meningkatkan kepatuhan pasien dalam menjalankan terapi(7). Oleh karenaitu, diharapkandenganadanyakomunikasi interpersonal antaraperawat dan pasienmakadapatmeningkatkankepatuhanminumobat pada pasien yang menderita diabetes mellitus. Tujuan penelitian ini adalah : Untuk mengetahui Hubungan Komunikasi Interpesonal Perawat Dengan Kepatuhan Minum Obat Pasien Diabetes Melitus di Puskesmas Pahandut Palangka Raya.

\section{METODE}

Desain penelitian yang digunakan deskriptif kuantitatif dengan rancangan studi korelasional. Jumlah sampel pada penelitian ini ditentukan menggunakan rumus besar sampel beda proporsi sebanyak 52 orang dengan teknik purposive sampling. Sampeldiambilberdasarkankriteriaberobat di PuskesmasPahandut, pernahberkomunikasidenganpetugaskesehatan, dan menggunakanobathipoglikemik oral (OHO); sampeltidakdiambiljikamengalami diabetes mellitus dengankomplikasikronissertamenggunakanterapifarmakologi insulin saja. Pengambilan data menggunakan instrument kuisioner yang terditidari data demografi (usia, jeniskelamin, tingkat Pendidikan, pekerjaan, lama menderitadiabete mellitus). Variabel kepatuhan minum obat dengan kuisionerthe 8 - Item Morisky Medication Adherence Scale (MMAS-8) (8)dengandengan penggolongan patuh (skor 6-8) dan tidak patuh (skor <6)(9). Hasil reliabilitas 0,76 dan validitas> 0,413 (cornbach alpha >0,6) (10). Variabelkomunikasi interpersonal menggunakan instrument 
kuisoner yang berisi 30 pertanyaanterdiridariketerbukaan, empati, sikapmendukung, sikappositif dan kesetaraan, hasil uji reliabilitas $>0,360$ dan uji validitas 0,724 (cornbach alpha $>0,6$ ) (11). Teknik analisis data terdiri dari analisis univariat dan bivariate. Analisis univariat menjelaskan masingmasing variable yang diteliti, adapun analisis bivariate dengan menggunakan analisis chisquare.Penelitiandilaksanakan dan disetujui oleh respondensetelahmenyertakaninformed consent (persetujuanuntukikutsertadalampenelitian). $\quad$ Penelitiantelahloloskajietikdengannomor 012

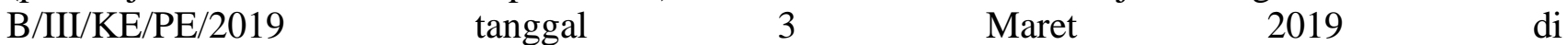
KomisiEtikpenelitianKesehatanPoltekkesKemenkesPalangka Raya.

\section{HASIL}

Penentuan responden berdasarkan usia dilakukan dengan mengkategorikan dalam 2 kategori, yaitu usia 26-45 tahun dan usia 46-65 tahun. Distribusi frekuensi data demografi responden dapat dilihat pada tabel berikut.

Tabel 1 Distribusi Frekuensi Karakteristik Responden di Puskesmas Pahandut Palangka Raya

\begin{tabular}{|c|c|c|c|}
\hline No. & Variabel & $\begin{array}{c}\text { Jumlah } \\
\text { (f) }\end{array}$ & $\begin{array}{c}\text { Presentase } \\
(\%)\end{array}$ \\
\hline \multirow[t]{3}{*}{1.} & Usia & & \\
\hline & 1. 26-45 tahun & 7 & 13,5 \\
\hline & 2. 46-65 tahun & 45 & 45 \\
\hline \multirow[t]{3}{*}{2.} & Jenis Kelamin & & \\
\hline & 1. Laki-laki & 14 & 26,9 \\
\hline & 2. Perempuan & 38 & 73,1 \\
\hline \multirow[t]{6}{*}{3.} & Pendidikan & & \\
\hline & 1. Tidak Sekolah & 1 & 1,9 \\
\hline & 2. SD & 14 & 26,9 \\
\hline & 3. SMP & 13 & 25,0 \\
\hline & 4. SMA & 13 & 25,0 \\
\hline & 5. Perguruan Tinggi & 11 & 21,2 \\
\hline \multirow{6}{*}{4.} & Pekerjaan & & \\
\hline & 1. IRT & 31 & 59,6 \\
\hline & 2. Buruh & 1 & 1,9 \\
\hline & 3. Wiraswasta & 5 & 9,6 \\
\hline & 4. PNS & 8 & 15,4 \\
\hline & 5. Pensiunan & 7 & 13,5 \\
\hline \multirow[t]{3}{*}{5.} & Lama Menderita DM & & \\
\hline & 1. 1-5 tahun & 33 & 63,5 \\
\hline & 2. $>5$ tahun & 19 & 36,5 \\
\hline
\end{tabular}

Hasil temuan diketahui bahwa mayoritas responden yang mengalami diabetes melitus berada dalam rentang usia 46-65 tahun dengan jumlah 45 responden (86,5\%) dan dalam rentang usia 26-45 tahun dengan jumlah 7 responden $(13,5)$.Karakteristik responden berdasarkan jenis kelamin, yang dominan menderita diabetes melitus adalah perenpuan dengan jumlah 38 responden $(73,1 \%)$ dan laki-laki sebanyak 14 responden (26,9\%). Data ini menunjukkan bahwa di Palangka Raya dan wilayah kerja Puskesmas Pahandut Palangka Raya diagnosis untuk diabetes melitus tipe 2 lebih banyak terjadi pada perempuan. Karakteristik responden berdasarkan pendidikan, yaitu sebanyak 1 orang tidak sekolah (1,9\%), sebanyak 14 orang dengan latar belakang pendidikan SD (26,9\%), sebanyak 13 orang dengan latar belakang pendidikan SMP (25,0\%), sebanyak 13 orang dengan latar belakang pendidikan SMA $(25,0 \%)$, dan sebanyak 11 orang dengan latar belakang perguruan tinggi $(21,2 \%)$. Karakteristik responden berdasarkan pekerjaan, yaitu sebanyak 31 responden bekerja sebagai IRT $(59,6 \%)$, sebanyak 1 responden bekerja sebagai buruh $(1,9 \%)$, sebanyak 5 responden bekerja sebagai wiraswasta $(9,6 \%)$, sebanyak 8 responden bekerja sebagai PNS $(15,4 \%)$, dan sebanyak 7 responden sebagai pensiunan (13,5\%). Disimpulkan bahwa responden yang bekerja sebagai IRT lebih banyak menderita diabetes melitus, sejumlah 31 orang $(59,6 \%)$. Pada penelitian ini 
ditemukan bahwa mayoritas responden yang menderita diabetes melitus dialami oleh ibu rumah tangga (IRT) sebanyak 31 responden $(59,6 \%)$.

Karakteristik responden berdasarkan lama menderita diabetes melitus, sebanyak 33 orang menderita diabetes melitus dalam rentang 1-5 tahun $(63,5 \%)$, dan sebanyak 19 orang menderita diabetes dalam rentang lebih dari 5 tahun (36,5\%). Disimpulkan bahwa lebih banyak responden yang menderita diabetes melitus dalam rentang 1-5 tahun sebanyak 33 orang $(65,5 \%)$. Pada penelitian ini ditemukan bahwa mayoritas responden yang menderita diabetes melitus rata-rata mengalami diabetes melitus dalam rentang 1-5 tahun sebanyak 33 responden $(63,5 \%)$.

Tabel 2. Distribusi Frekuensi PersepsiResponden Dengan Diabetes Melitus Terhadap Tingkat Komunikasi Interpersonal Perawat di Puskesmas Pahandut Palangka Raya Tahun 2019

\begin{tabular}{ccc}
\hline Tingkat Komunikasi & Jumlah (f) & Presentase (\%) \\
\hline Komunikasi Baik & 39 & 75,0 \\
\hline Komunikasi Tidak Baik & 13 & 25,0 \\
\hline Total & 52 & 100
\end{tabular}

Penelitian yang dilakukan terhadap 52 responden dengan diabetes melitus mengenai persepsi responden dengan diabetes melitus terhadap tingkat komunikasi interpersonal perawat yang dilakukan perawat selama responden diberikan asuhan keperawatan di Puskesmas Pahandut Palangka Raya, yaitu komunikasi baik sebanyak 39 orang $(75,0 \%)$ dan komunikasi kurang baik sebanyak 13 orang $(25,0 \%)$.

Tabel 3. Distribusi Frekuensi Tingkat Kepatuhan Minum Obat Pada Responden Dengan DiabetesMelitus di Puskesmas Pahandut Palangka Raya Tahun 2019.

\begin{tabular}{lcc}
\hline Tingkat Kepatuhan & Jumlah (f) & Presentase (\%) \\
\hline Patuh & 29 & 55,8 \\
\hline Tidak Patuh & 23 & 44,2 \\
\hline Total & 52 & 100 \\
\hline
\end{tabular}

Penelitian yang dilakukan terhadap 52 responden terhadap tingkat kepatuhan minum obat, pada pasien diabetes melitus di Puskesmas Pahandut Palangka Raya, yaitu tingkat kepatuhan pada kategori patuh sebanyak 29 orang $(55,8 \%)$, dan tingkat kepatuhan pada kategori tidak patuh yaitu sebanyak 23 orang (44,2\%). Hasil dari data tersebut dapat disimpulkan bahwa tingkat kepatuhan minum obat pada pasien diabetes melitus di Puskesmas Pahandut Palangka Raya sebagian besar dalam kategori patuh. Hal ini hampir sama dengan penelitian sebelumnya tentang faktor-faktor yang berhubungan dengan kepatuhan berobat pasien diabetes melitus pada praktek dokter keluarga di Kota Tomohon terhadap 96 responden diperoleh hasil sebanyak 78 responden $(81,3 \%)$ patuh dalam berobat.

Tabel 4. Analisis Hubungan Komunikasi Interpersonal Perawat terhadap Tingkat Kepatuhan Minum Obat pada Responden di Wilayah Kerja Puskesmas Pahandut Palangka Raya Tahun 2019.

\begin{tabular}{|c|c|c|c|c|c|c|c|c|}
\hline \multicolumn{5}{|c|}{ Kepatuhan } & \multirow{2}{*}{\multicolumn{2}{|c|}{ Total }} & \multirow{3}{*}{ OR } & \multirow{2}{*}{$\begin{array}{c}\mathrm{P}- \\
\text { value }\end{array}$} \\
\hline \multirow[t]{2}{*}{ Komunikasi } & \multicolumn{2}{|c|}{ Patuh } & \multicolumn{2}{|c|}{ Tidak Patuh } & & & & \\
\hline & $\mathrm{F}$ & $\%$ & $\mathrm{~F}$ & $\%$ & $\mathrm{~F}$ & $\%$ & & \\
\hline Baik & 22 & 75,9 & 17 & 73,9 & 39 & 75,0 & & \\
\hline Tidak Baik & 7 & 24,1 & 6 & 26,1 & 13 & 25,0 & $\begin{array}{c}1,109 \\
(0,92-\end{array}$ & 0,000 \\
\hline Total & 29 & 100 & 23 & 100 & 52 & 100 & $2,50)$ & \\
\hline
\end{tabular}


Hasil analisis menggunakan uji statistik chi-square, didapatkan OR 1,109 pada (95\% CI : 0,92 2,50) $\quad \mathrm{P}-$ Value $\leq 0,001$ halinimenunjukkanhubungan yang erat antara komunikasi interpersonal perawat terhadap kepatuhan minum obat Pasien Diabetes Melitus Tipe 2 di Puskesmas Pahandut Palangka Raya. Responden yang mengalami komunikasi interpersonal yang tidak baik berisiko atau berpotensi 1,109 kali untuk mengalami ketidakpatuhan minum obat antidiabetes dibandingkan dengan responden yang mengalami komunikasi interpersonal baik.

\section{PEMBAHASAN \\ DemografiResponden}

Data demograsi respondenya itu usia, jenis kelamin, tingkat Pendidikan, pekerjaan, lama menderita diabetes mellitus. Bertambahnya usia maka akan meningkatkan risiko terkena diabetes tipe 2. Seseorang yang paling sering menderita diabetes melitus berumur antara 45-64 tahun(12). Palangka Raya dan wilayah kerja Puskesmas Pahandut Palangka Raya diagnosis untuk diabetes melitus tipe 2 lebih banyak terjadi pada perempuan. Hal ini dipengaruhi kadar lipid pada perempuan lebih tinggi dibandingkan pada laki-laki, sehingga faktor risiko terjadinya diabetes melitus pada perempuan 3-7 kali lebih tinggi dbandingkan pada laki-laki yaitu 2-3 kali(13). Tingkat Pendidikan Sekolah Dasar (SD) sebagian besar menderita diabetes mellitus, hal ini sejalan dengan penelitian yang menyatakan bahwa terdapat hubungan antara tingkat pendidikan dengan kejadian diabetes melitus tipe 2. Pendidikan yang kurang akan menghambat perkembangan sikap seseorang terhadap nilai-nilai atau informasi yang baru diperkenalkan, sebaliknya makin tinggi tingkat pendidikan seseorang semakin mudah pula menerima informasi, sehingga semakin banyak pula pengetahuan yang dimiliki(14).Mayoritas responden penderita diabetes adalah ibu rumah tangga (IRT). Jenis pekerjaan dapat memicu timbulnya penyakit melalui ada tidaknya aktivitas fisik di dalam pekerjaan, sehingga dapat dikatakan pekerjaan seseorang mempengaruhi tingkat aktivitas fisiknya. Kejadian diabetes melitus yang banyak dialami oleh IRT terjadi karena beberapa faktor, yaitu usia lanjut (lansia) dimana menyebabkan efek antagonis hormone estrogen dan progesteron terhadap pelepasan insulin yang menyebabkan resistensi insulin dalam tubuh, kelebihan berat badan menjadi salah satu faktor penyebab banyaknya IRT yang mengalami diabetes melitus, dan beberapa responden melaporkan bahwa memiliki riwayat keturunan keluarga dengan diabetes melitus(15).Pada penelitian ini ditemukan bahwa mayoritas responden yang menderita diabetes melitus rata-rata mengalami diabetes melitus dalam rentang 1-5 tahun sebanyak 33 responden $(63,5 \%)$. Hal ini sejalan dengan penelitian bahwa lama menderita diabetes melitus sangat mendukung terhadap pengetahuan dalam penggunaan obat, semakin lama responden menderita diabetes melitus maka pengalamannya terhadap penyakit tersebut juga akan bertambah. Semakin banyak pengalaman seseorang, maka semakin baik pula pengelolaan penyakit dan penanganannya(16).

\section{Komunikasi dan Kepatuhan}

Sebagian besar komunikasi interpersonal perawat yang ada di Puskesmas Pahandut Palangka Raya dalam tingkat komunikasi baik. Pada penelitian ini komunikasi interpersonal perawat sudah baik. Hal ini dipengaruhi oleh aspek komunikasi keterbukaan, empati, sikap mendukung dan kesetaraan yang menciptakan terbinanya hubungan saling mendukung antara pasien dan perawat sehingga pola komunikasi menjadi optimal dan penerimaan pesan menjadi positif. Keterbukaan dalam komunikasi interpersonal memiliki pengertian bahwa dalam komunikasi antar pribadi yang efektif, individu harus terbuka pada pasangan yang diajak berinteraksi, kesediaan untuk membuka diri dan memberikan informasi, lalu kesediaan untuk mengakui perasaan dan pikiran yang dimiliki dan juga mempertanggung jawabkannya(17).

Kepatuhan adalah tingkat perilaku penderita dalam mengambil suatu tindakan pengobatan, misalnya dalam menentukan kebiasaan hidup sehat dan ketetapan berobat. Dalam pengobatan, seseorang dikatakan tidak patuh apabila orang tersebut melalaikan kewajibannya berobat, sehingga dapat mengakibatkan terhalangnya kesembuhan(18). Seseorang dikatakan patuh berobat bila mau datang ke petugas kesehatan yang telah ditentukan sesuai dengan jadwal yang telah ditetapkan serta mau melaksanakan apa yang dianjurkan oleh petugas dokternya atau yang lain(19). Banyak faktor 
yang menyebabkan ketidakpatuhan responden terhadap minum obat antidiabetes dan pengobatannya pada penelitian ini, terbatasnya alat transportasi ke pusat pelayanan kesehatan terdekat sehingga menghambat proses pengobatan, lupa minum obat, jenuh karena harus minum obat setiap hari, merasa sakit semakin parah jika minum obat setiap hari, mengikuti anjuran kerabat dan keluarga untuk mengkonsumsi ramuan herbal.

Kepatuhan minum obat merupakan salah satu keberhasilan dalam penatalaksanaan diabetes melitus, pada dasarnya penatalaksanaan diabetes melitus bertujuan untuk mengendalikan kadar gula darah dan meningkatkan kualitas hidup dan mencegah komplikasi, kepatuhan minum obat salah satunya dipengaruhi oleh komunikasi interpersonal perawat selama pasien menjalani pengobatan. Sikap mendukung petugas kesehatan memberi pengaruh terhadap kepatuhan pasien, dimana pasien mendapat dukungan motivasi dari petugas kesehatan untuk selalu tepat waktu mengambil obat ke puskesmas dan selalu memperhatikan perkembangan kesehatan pasien, sehingga pasien merasa diperhatikan oleh petugas dan menerima semua anjuran petugas selama pengobatan(20). Hal ini dibuktikan dengan hasil penelitian bahwa dari 29 responden yang diteliti, 22 orang masuk dalam kategori patuh minum obat dengan tingkat komunikasi interpersonal perawat baik dan 7 responden dengan tingkat komunikasi interpersonal perawat kurang baik. Sementara dari 24 orang yang termasuk dalam kategori tidak patuh minum obat, 17 orang dengan tingkat persepsi komunikasi interpersonal perawat baik dan 6 responden dengan persepsi tingkat komunikasi interpersonal perawat kurang baik. Sejalan dengan penelitian yang dilakukan oleh Damayanti dan Fuadi (2015) dari 84 responden yang diteliti 56 responden yang menyatakan teknik komunikasi baik sebanyak 33 responden $(58,9 \%)$ patuh dalam berobat dan 23 orang $(41,1 \%)$ tidak patuh berobat, sedangkan dari 28 responden yang menyatakan teknik komunikasi kurang baik, 24 responden $(85,7 \%)$ patuh berobat dan 4 responden $(14,3 \%)$ tidak patuh berobat. Hasil penelitian terkait, bahwa salah satu strategi untuk meningkatkan ketaatan adalah memperbaiki komunikasi antara petugas kesehatan dengan pasien dari aspek keterbukaan, empati, sikap mendukung dan kesetaraan. Sehingga terbina hubungan saling mendukung yang secara tidak langsung dapat menciptakan penerimaan informasi yang yang positif bagi pengobatan pasien(21). Semakin baik komunikasi interpersonal perawat maka semakin baik pula kepatuhan orang terbut dalam menjalankan terapi dan pengobatannya, sementara semakin kurang baik komunikasi interpersonal perawat maka resiko untuk tidak patuh dalam menjalankan terapi dan pengobatan akan semakin tinggi. Pentingnya faktor keterampilan komunikasi interpersonal perawat terhadap kepatuhan minum obat pasien diabetes melitustelah diungkap dalam penelitian ini, maka disarankan bagi pihak institusi pelayanan kesehatan dapat memperhatikan dan menjadi fasilitator bagi para perawat untuk meningkatkan komunikasi interpersonal sebagai salah satu faktor pendukung kepatuhan pengobatan pasien diabetes melitus

\section{SIMPULAN}

Karekteristik responden yang paling banyak mengalami diabetes melitus dalam penelitian ini adalah lansia, perempuan, pendidikan SD, IRT dan mayoritas lama menderita diabetes mellitus pada rentang 1-5. Persepsi responden terhadap tingkat komunikasi interpersonal perawat di Puskesmas Pahandut Palangka Raya dalam kategori baik. Terdapat hubungan yang bermakna antara antara variable Komunikasi Interpersonal Perawat terhadap Kepatuhan Minum Obat Pasien Diabetes Melitus tipe 2 di Puskesmas Pahandut Palangka Raya.

\section{SARAN}

Disarankan bagi pihak institusi pelayanan kesehatan dapat memperhatikan dan menjadi fasilitator bagi para perawat untuk meningkatkan komunikasi interpersonal sebagai salah satu faktor pendukung kepatuhan pengobatan pasien diabetes melitus. Hendaknya mempelajari dan melatih keterampilan komunikasi interpersnal dengan pasien agar terjalin hubungan interpersonal yang hangat dengan pasien, dan meningkatkan kepatuhan pengobatan dan minum obat pada pasien dengan diabetes melitus 


\section{DAFTAR PUSTAKA}

1. Association AD. Diagnosis and Classification of Diabetes Mellitus. American Diabetes Care. 2015;38:8-16.

2. Aini N. FW, Yusuf A. . Upaya Meningkatkan Perilaku Pasien Dalam Tatalaksana Diabetes Melitus Dengan Pendekatan Teori Model Behavioral System Dorothy E. Johnson. Jurnal Ners. 2011;6:1-10.

3. Federation ID. IDF Diabetes Atlas 7th Edition. French: International Diebetes Federation; 2015.

4. Riskesdas. Riset Kesehatan Dasar (Riskesdas) Jakarta: Badan Penelitian dan Pengembangan Kesehatan Kementerian Kesehatan; 2018.

5. RI K. Profil Kesehatan Republik Indonesia 2017. Jakarta: Pusat Data dan Informasi Kemenkes RI; 2018.

6. Udayani NNW. Analisis Penggunaan Obat Hipoglikemik dan Dislipidemia Oral Pada Pasien Diabetes Melitus Tipe 2 dengan Komplikasi Dislipidemia Rawat Jalan di Rumah Sakit Panti Rapih Yogyakarta. Yogyakarta: Universitas Gadjah Mada; 2011.

7. Niven N. Psikologi Kesehatan : Pengantar untuk Perawat dan Profesional Kesehatan Lain. Jakarta: EGC; 2012.

8. D.E. Morisky AA, M. Krousel-Wood, H.J. Ward The Morisky 8-Item Self Report Measure of Medication Taking Behaviour (MMAS-8). Journal of Clinical epidemiology. 2011;64:262-3.

9. N. Shams SA, N. Kumar, W. Ahmed, F. Saleem. Drug Non-Adherence in Type 2 Diabetes Mellitus; Predictors and Associations. J Ayug Med Coll Abbottabad. 2016;28(2).

10. Ardanti RF. Hubungan Persepsi Dukungan Keluarga Terhadap Kepatuhan Minum Obat Pada Paseian Diabetes mellitus di Puskesmas 1 Gamping. Yogyakarta: Universitas Muhammadyah Yogyakarta; 2016.

11. Tamara PV. Gambaran Persepsi Pasien BPJS Dan Non BPJS Tentang Komunikasi Interpersonal Petugas Kesehatan Di Puskesmas Kecamatan Cinangka Serang Banten. Jakarta: Universitas Islam Negeri Syarif Hidayatullah Jakarta; 2017.

12. Association AD. Standars of Medical Care in Diabetes. America: The American Diabetes Association; 2017.

13. Haryati G. Hubungan Faktor Resiko, Jenis Kelamin, Kegemukan dan Hipertensi dengan Kejadian Diabetes Melitus Tipe II di Wilayah Kerja Puskesmas Mataram. Meida Bina Ilmiah. 2015;8(1).

14. Ida Gde Ayu Dharmawati INW. Hubungan Tingkat Pendidikan, Umur dan Masa Kerja dengan Tingkat Pengetahuan Kesehatan Gigi dan Mulut pada Gurus Penjaskes di Kecamatan Tampak Siring Gianyar. Jurnal kesehatan Gigi. 2016;5(1).

15. Shara Kurnia Trisnawati SS. Faktor Risiko Kejadian Diabetes Melitus Tipe II Di Puskesmas Kecamatan Cengkareng Jakarta Barat tahun 2012. Jurnal Ilmiah Kesehatan. 2013;5(1).

16. H. Pramestutie NS. Tingkat Pengetahuan Pasien Hipertensi tentang Penggunaan Obat di Puskesmas Kota Malang. Jurnal Farmasi Klinik Indonesia. 2016.

17. Effendy OU. Ilmu Komunikasi Teori dan Praktik. Bandung: PT. Remaja Rosdakarya; 2013.

18. Niven N. Psikologi Kesehatan : Pengantar Untuk Perawat \& Profesional Kesehatan Lain. Jakarta: EGC; 2012.

19. Puspa Pameswari AH, Lisa Yustika. Tingkat Kepatuhan Penggunaan Obat pada Pasien Tuberkulosis di Rumah Sakit Mayjen H.A. Thalib Kabupaten Kerinci. Jurnal Sains Farmasi \& Klinis. 2016;2(2).

20. Dermawanti RKR, Tukiman. Hubungan Komunikasi Interpersonal Petugas Kesehatan Terhadap Kepatuhan Pasien Menjalani Pengobatan TB Paru di Puskesmas Sunggal Medan Tahun 2014. Medan: Universitas Sumatra Utara; 2014.

21. Damelta Hutagaol LSA, Eddy Syahrial. The Factors Associated with Health Workesr in Interpersonal Communication Satisfications of outpatient health Center. Medan: Universitas Sumatra Utara; 2014. 